\title{
Decision Planning in Agricultural Production to Achieve a Green Economy in Mae Faek Sub-District, Chiang Mai Province, Thailand
}

\author{
Kamontip Panyasit ${ }^{1}$ \\ Montri Singhavara ${ }^{2}$ \\ Aree Cheamuangphan ${ }^{2}$ \\ Sakkarin Nonthapot ${ }^{1 *}$ \\ ${ }^{1}$ Faculty of Interdisciplinary Studies, Khon Kaen University, Nong Khai Campus, Thailand 43000 \\ ${ }^{2}$ Faculty of Economics, Maejo University, Thailand 50290 \\ *Corresponding author: sakkno@kku.ac.th
}

Article History: Received: 10 November 2020; Revised 12 January 2021 Accepted: 27 January 2021; Published online: 5 April 2021

\begin{abstract}
The research aims to study decision making using producing factors under the concept of green economy to enhance the community's economic sustainability for 250 agricultural households who grow glutinous rice, animal feed maize and potato in an area of 2,500 Rai in Mae-Faek Mai Sub-District, Sansai District, Chiang Mai Province. The study employs the Fuzzy Analysis Hierarchical Process (FAHP) together with Multi-goal and Multi-Period Linear Programming. The results reveal that growing in-season glutinous rice alternating with potato is the most appropriate way to increase net revenue and to decrease the amount of greenhouse emission, followed by growing in-season glutinous rice alternating with animal feed maize as this helps income stability when drought occurs. In contrast, growing in-season glutinous rice alternating with off-season glutinous rice is not only affected by a lack of water resources, but also increases the amount of greenhouse gas from the growing process.
\end{abstract}

Keywords: Multi-criteria decision, Fuzzy Analysis Hierarchical Process

\section{Introduction}

The 11th National Economic and Social Development Plan established many important strategies to encourage sustainable and environmentally-friendly production and consumption to move towards a green economy. Activities under this approach include using resources efficiently, reducing greenhouse gas emissions, not causing imbalances in order to sustain human life and to support the way of life of people in every sector (Ministry of Agriculture and Cooperatives 2013). This approach is a significant factor in sustainable development (Newton and Cantarello, 2014) Moreover, the ministry has established zoning for economic crops in each area through collaborative farming. The goal is to grow crops according to the potential of each area and to reduce costs to make agricultural production more competitive. In practice, this means cooperating with agriculturists in the area to plan production and marketing.

Mae Faek Mai Sub-District, Sansai District is an important growing area for economic crops in Chiang Mai. It has both plain and highland landscapes large enough to grow crops. It also has fertile soil, good water and irrigation and is suitable for many economic crops, especially rice, maize and potato, which are considered as important economic crops in Thailand. However, the previous approach of the agriculturist community focused on marketing, which had the following negative impacts on the economy, environment and society: 1) agricultural household debt is rising as a result of rising costs and falling prices, which leads to ongoing and continuous deficits; 2) there is environment uncertainty as a result of drought and flood, resulting in the need for water resource planning. In addition, climate change also directly affects the crop yield. These factors resulted in farmers using more chemical fertilizers, which affect soil fertility and cause chemical contamination of the natural water supply.

As a result of the abovementioned issues, which affect policy in Thailand and the world in general, there is a need to move toward the concept of green economy and sustainable economic growth for the sake of the economy, society and the environment. However, these goals contradict one another, which makes it difficult to plan or manage local resources in reality. Therefore, this research aims to analyze resource management decision making 
to achieve community goals and greenhouse emission targets based on the concept of the green economy in order to make the community's economy sustainable.

\section{Literature review}

Multiple criteria decisions making (MCDM) and multiple objective decision making (MODM) are widely accepted by sustainable agricultural and energy development researchers. This is because the objective of such research involves society, the economy and the environment, which are considered as important factors in a green economy. Researchers who applied MCDM and MODM to achieve sustainability identified the following steps: 2) selecting criteria; 2) weighting; and 3) analysis of MCDM. The criteria can be divided into four types: (1) technical criteria which are mostly related to efficiency; (2) economic criteria, which focus on lowering costs and increasing economic benefits (Jovanovic et al., 2009); (3) environmental criteria, which include the emission of NOx and $\mathrm{CO} 2$ and include land use for agriculture that directly affects the environment and landscape (Pilavachi et al., 2009); (4) social criteria, which include job creation, which increases income and enhances the quality of life of people in the community (Doukas et al., 2007). Weighting is significant approach in prioritizing criteria and alternatives. The most widely-used weighting methods can be classified into two types: 1) subjective weighting i.e., weighting by using satisfaction scores from decision makers such as AHP (Aras H, 2004) where the weighting for each level can be calculated in many ways e.g., arithmetic mean; 2) objective weighting i.e., calculating the weighting for example, by using the Entropy method, whereby value dispersion is measured (Wang et al., 2008). Moreover, conventional MCDM assumes values to be definite, but in reality, most decision making takes place in uncertain and fuzzy situations. An application of Fuzzy Set Theory was presented by Zadeh in 1965 and employed MCDM for energy evaluation in which economic, social and environment factors were included (Wang et al., 2008). MCDM was employed to select the best potential supplier for VMI collaboration in a healthcare organization (Sumrit, 2020). There is participation by decision makers in MCDM analysis such as MODM (as in Chebyshev Goal Programming) together with Fuzzy Analysis Hierarchical Process (FAHP). This was employed in research on the allocation of land usage in Holland (Stewart et al., 2004), and in a model for crop growing in India with Fuzzy goal programming (FGP) (Biswas, 2005). Moreover, calculating the result of MODM yields a ratio of trade-offs that reflect resource scarcity. Beck et al. (2008) set goals in an energy plan and calculated trade-offs between economy, society and environment to determine the opportunity cost that resulted from the selection of various alternatives.

\section{Methodology}

This study employs MCDM which consists of two main parts: 1) Fuzzy Analysis Hierarchical Process (FAHP), which is used to determine the weight value that agriculturists give to alternatives in crop growing and selling; 2) Developing a Multi-Period and Multi-goal Linear Programming model (MpMGP) together with Extended goal programming (EGP). The weight values from FAHP are used in the objective equation for the mode of EGP as follows.

\subsection{Population and sampling}

To facilitate area-use planning, the researchers identified potential areas and a sampling population who were willing to provide information and areas in Mae Faek Mai, Sansai District, Chiang Mai were selected. The types of crops grown included the following: 1) in-season glutinous rice alternating with potato; 2) in-season glutinous rice alternating with maize for animal feed; and 3) in-season glutinous rice alternating with off-season glutinous rice. The total population growing those three types of crop totaled 420 households. When considering the size of the sample based on Krejcie \& Morgan's method (Cochran, 1997 cited in Nonthapot \& Thomya, 2020; Nonthapot \& Nasoontorn, 2020) together with readiness for a collaborative production plan, the sample size is 250 households. Field data collection was conducted in the crop growing year 2016-2017 together with secondary data from statistics and relevant research in order to acquire the parameter values for the model.

\subsection{Data analysis methods}

1) Decision making using the Fuzzy Analysis Hierarchical Process) FAHP( is a multi-criteria decision making process )MCDM (to solve complex and fuzzy problems by using the best alternatives. This includes the concept of fuzzy set theory together with MCDM for pairwise comparison that is uncertain or fuzzy. Such a process is applied with participatory meetings to determine the weight values for the criteria and alternatives.

2) The development of Multi-Period and Multi-goal Linear Programming) MpMGP( from participatory meetings yield an objective equation. That is, the highest revenue from the objective number; 1) in-season glutinous rice alternating with potato; 2) in-season glutinous rice alternating with maize for animal feed and 3) inseason glutinous rice alternating with off-season glutinous rice. For the objectives 1) -3), we include greenhouse gas emissions from the first three alternative equations to be objective numbers 4-6. Moreover, crop growing is divided into three parts: growing, taking care, and harvesting and selling. To make it a continuous production 
plan, the multi-period model includes a 48-month period for decisions as shown by the following model and parameters. The steps of MpMGP are as follows:

(2.1 ( he objective equation is presented as the highest net revenue objective equation) $Z_{b}$ (for growing and selling products from three alternatives (with the FAHP method

$$
\begin{aligned}
Z_{b}= & \sum_{t=1}^{T}\left(P_{i t} \cdot Y_{i t}\right) \cdot \text { Area }_{i t(j=3)}-\sum_{t}^{I} \sum_{t=1}^{T} \sum_{j=1}^{J}\left(C l_{i j}\right) \cdot \text { Area }_{i t j}-\sum_{t}^{I} \sum_{t=1}^{T} \sum_{j=1}^{J}\left(C H_{i j}\right) \cdot H i L a_{i t j} \\
& -\sum_{t}^{I} \sum_{t=1}^{T} \sum_{j=1}^{J}\left(C W_{i j}\right) \cdot H i W_{i t j} \quad \forall b \quad b=1, \ldots, 3
\end{aligned}
$$

The objective equation for the lowest $\mathrm{CO} 2$ amount $) Z_{c}$ (from growing according to equation) 1 (, is as follows:

$$
Z_{c}=\sum_{i}^{I} \sum_{t=1}^{T}\left(F C_{i} \cdot Y_{i t}\right) \cdot \operatorname{Area}_{i t(j=3)} \quad \forall c \quad c=4, \ldots, 6
$$

The selling price of product $\left(P_{i t}\right)$ and the average yield of crops $\left(Y_{i t}\right)$ from a field survey of agriculturists sampled during crop seasons 2013 - 2017 were arranged lowest - highest. This is because each agriculturist has different production efficiency, so there is much variation resulting in uncertain, fuzzy information. Moreover, the amount of $\mathrm{CO} 2$ from crop growing can be calculated from the average crop yield $\left(Y_{i t}\right)$ and timing with a value for $\mathrm{CO}$ emissions for each crop $\left(F C_{i t}\right)$ ) Thailand Greenhouse Gas Management Organization, 2017 (as shown in Table 1. Moreover, the cost of producing crops $\left(C l_{i t}\right)$ can be obtained by using data from crop year 2014/15 from glutinous rice farmers (both in and off season), maize for animal feed, and potato, so the average budget relevant to important production activities i.e. growing (hired labor, seeds, and soil preparation), taking care (hired labor, fertilizer, hormone and crop pesticide), and harvest (hired labor) can be obtained as shown in

\begin{tabular}{|c|c|c|c|c|c|c|}
\hline \multirow{2}{*}{ crops } & \multicolumn{3}{|c|}{$\begin{array}{l}\text { Cost of production } \\
\text { (baht/Rai) }\left(C l_{i t}\right)\end{array}$} & \multirow{2}{*}{$\begin{array}{c}\text { Average price } \\
\text { (baht/Kg.) } \\
\left(P_{i t}\right)\end{array}$} & \multirow{2}{*}{$\begin{array}{c}\text { Average yield } \\
\text { (Kg./Rai) } \\
\left(Y_{i t}\right)\end{array}$} & \multirow{2}{*}{$\begin{array}{c}\text { CO amount } \\
(\mathrm{kgCO} / \mathrm{Rai}) \\
\left(F C_{i} \cdot Y_{i t}\right)\end{array}$} \\
\hline & grow & care & harvest & & & \\
\hline In-season glutinous rice & 2,314 & 1,016 & 600 & $8.5-15$ & $650-1,000$ & $991.25-1,525$ \\
\hline Off-season glutinous rice & 2,770 & 876.6 & 714 & $9.5-15$ & $600-800$ & $759.6-1,012.8$ \\
\hline Maize for animal feed & 2,075 & 770 & 733 & $6.5-9$ & $722-750$ & $192.7-200.2$ \\
\hline Potato & 5,880 & 3,275 & 475 & $9.5-12.5$ & $2,800-3,500$ & $341.6-427$ \\
\hline
\end{tabular}
Table 1.

Table 1. Parameter value of objective equation

Source: from the survey

(2.2 (Equation of Constraints comprises water and soil resources and labor.

(2.2.1) Constraints in water resources include water transfer during dry and rainy seasons, including the amount of water used in crop growing as set by zoning as shown in equation) 3 (

$$
\begin{gathered}
\operatorname{Tr}_{t(w=1)}-\operatorname{HiW}_{t(w=2)} \leq \operatorname{WatQ}_{t(w=1)} \quad \exists t \\
\operatorname{Tr}_{t(w=1)}-\operatorname{HiW}_{t(w=2)} \leq \operatorname{Wat}_{t(w=1)} \quad \exists t \\
\sum_{i=1}^{I} \sum_{J=1}^{j}\left(C W U_{t j}\right) \cdot \text { Area }_{i t j}+\operatorname{Tr}_{t(w=1)}-\operatorname{Tr}_{(t-1)(w=1)} \leq \operatorname{Wat}_{t(w=3)} \quad \exists t \quad \exists i
\end{gathered}
$$

The constraints of groundwater usage during dry and rainy seasons are shown in equation) 4(

$$
\begin{array}{ll}
\sum_{t=1}^{T} H_{i} W_{t(w=2)} \leq W Q R_{w=2} & \exists t \\
\sum_{t=1}^{T} H_{i} W_{t(w=4)} \leq W Q R_{w=4} & \exists t
\end{array}
$$

Where the amount of irrigation water is $\left(W a t Q_{t w}\right)$ groundwater is $(W Q R)$ and the ratio of water usage by crop is $\left(C W U_{i j}\right)$.

Since the studied areas are in an irrigated system, the lack of water is not a problem. However, due to climate uncertainty, the amount of water is set as fuzzy. From the interviews with agriculturists and irrigation experts, 
we know that the amount of water that can be used for agriculture during dry season (Jan - May) is 70-550 thousand cubic meters/month, and during the rainy season (Jun - Aug), it is 550-1, 000thousand cubic meters/month) Irrigation Department, 2014(. Moreover, Mae Faek Mai can use groundwater as reserve water. From the estimation of experts, this amount totals around $0-50$ thousand cubic meters/month. For ratio of water used by crops $\left(C W U_{i j}\right)$, off-season glutinous rice has the highest ratio as shown in Table 2 .

(2.2.2 (Constraints on appropriate zones for crop growing in the studied areas: the overall use of land for all crop growing activities would have values not over the size of soil series $\left(\right.$ Aland $\left._{s t}\right)$

$$
\sum_{i=1}^{I} \sum_{j=1}^{J} \text { Area }_{i t j} \leq \text { Aland }_{s t} \forall t \forall i
$$

The area for harvest and taking care activities are less than that for growing.

$$
\begin{aligned}
& \operatorname{Area}_{i(t+1)(j=2)} \leq \operatorname{Area}_{i(t) j(j=1)} \forall t \forall i \\
& \operatorname{Area}_{i(t+2)(j=2)} \leq \operatorname{Area}_{i(t+1)(j=2)} \forall t \forall i \\
& \operatorname{Area}_{i(t+3)(j=3)} \leq \operatorname{Area}_{i(t+2)(j=2)} \forall t \forall i
\end{aligned}
$$

When the area is determined to be suitable for crop growing $\left(\operatorname{Aland}_{i t}\right)$, soil series is used for decision planning and includes soil that is suitable based on altitude and irrigation at around 5, 436Rai.) Land Development Department, 2007. ( However, to make management efficient with in-time practicality, stakeholders decided that land use would be $45 \%$ or roughly 2,500 Rai.

2.2.3 (Constraints on household labor and hired labor for growing and harvesting activities. Equation No.) 6 ( is the use of labor for activity of crop $i$ which has a value no more than that for household labor $\left(A L_{t}\right)$ plus hired labor $\left(H i L_{i t}\right)$

$$
\sum_{i=1}^{I} \sum_{j=1}^{J}\left(L Q_{i j}\right) \cdot \text { Area }_{i j t}-\sum_{i=1}^{I} H i L_{i t} \leq A L_{t} \quad \exists i \quad \forall t
$$

The highest amount of hired labor for crop $i$ at time $t$ has a value no more than that for hired labor. $\left(A H i L_{t}\right)$

$$
\sum_{i=1}^{I} H i L_{i t} \leq A H i L_{t} \quad \exists i \quad \forall t
$$

The ratio of labor usage in the growing activity $\left(L Q_{i j}\right)$ is obtained from the field survey on labor use for growing, taking care and harvesting (Table 2.) Growing includes soil and seed preparation, and growing seeds. These are activities that use the most average man-hours. Potato is the crop that needs more care than any other crop. Maize for animal feed uses the least average man-hours since it is easy to take care of it, it can withstand drought, and it is not affected much by disease. Agriculturists use only household labor to grow it.

Table 2. Man-hour use for growing activities and water usage for crops

\begin{tabular}{|l|c|c|c|c|}
\hline \multirow{2}{*}{\multicolumn{1}{|c|}{ crops }} & \multicolumn{2}{c|}{ Labor use (man-hour/Rai) } & \multirow{2}{*}{$\begin{array}{c}\text { Water used by crops } \\
\text { cbm/Rai }\left(C W U_{i j}\right)\end{array}$} \\
\cline { 2 - 4 } & grow & care & harvest & $1,050-650$ \\
\hline In-season glutinous rice & 18.0 & 6.4 & 12.5 & $2,009-750$ \\
\hline Off-season glutinous rice & 17.5 & 7.1 & 13.0 & $600-400$ \\
\hline Maize for animal feed & 16.0 & 3.1 & 10.5 & $650-500$ \\
\hline Potato & 24.0 & 8.0 & 16.0 & \\
\hline
\end{tabular}

Source: from the survey

In regard to the amount of household labor $\left(A L_{t}\right)$ and hired labor already living in the area $\left(A H i L_{t}\right)$ there are, on average, three members working in agriculture per household. Hired labor in the studied and nearby areas was, on average, $25-200$ persons.) Chiang Mai Community Development Department, 2016 (Assuming 1 person works 8 hours per day and 25 days per month, the number of hours of household labor is 5,000 and for hired labor, it is 5,000 -40,000 man-hours/ month.

For the Specifying Sets,

$i$ is type of crop $i \in I I=1$ in-season glutinous rice $I=2$ off-season glutinous rice $I=3$ potato $I=4$ maize for animal feed

$s$ is type of suitable soil series $s \in S \quad S=1$ number one suitable soil series

$t$ is time period of agricultural activities $t \in T$ month $1-48$

$j$ is crop growing activity $j \in J \quad J=1$ growing $J=2$ taking care $J=3$ harvesting 
$w$ water supply in growing areas $w \in W \quad W=1$ irrigation water $W=2$ groundwater

The decision variables are as follows:

$A r e a_{i t j}$ is land usage of crop $i$ for growing activityjat time $t$ with suitable soil seriess )unit: Rai(

$H i L a_{i t j}$ is amount of hired labor (unit: man-hour)

$H i W_{i t j}$ is amount of groundwater usage during dry and rainy seasons at time $t$ ) unit: cubic meter

$\operatorname{Tr} W_{t w}$ is amount of irrigation left from agricultural activities at time $\left.t\right)$ unit: cubic meter (

$\operatorname{Tr} W_{(t-1) w}$ is amount of irrigation water transferred at time $\left.t\right)$ unit: cubic meter(

$H i L_{i t}$ is amount of hired labor at time $\left.t\right)$ unit: man-hour(

Since some decision variables are uncertaina e.g., economic factors (product price, labor amount), environmental factors (water amount, crop yield) and the $\mathrm{CO}$ goal, the membership function is set as Fuzzy min while the goal value for net revenue has a membership function set as Fuzzy max) Sakawa, Yano \& Nishizaki, 2013(

\section{3( Finding appropriate values by extended goal programming )EGP(}

Since the results of the multi-purpose and multi-period model yield many values for efficient resource allocation according to the Pareto principle, this can cause imbalances in the results. That is, only crops that have efficiency in income are selected to be grown. So, to set criteria for choosing appropriate alternatives, the EGP model is applied so that resource allocation would be a balance between efficiency, or weighted goal programming )WGP (and equity or Chebyshev goal programming )CGP) (Jones et al., (2016. Consequently, the EGP model can demonstrate the possible combination of two contradictory entities: efficiency and equity based on the goal.

\section{Results}

\subsection{Making decisions with the Fuzzy Analysis Hierarchical Process :(FAHP (}

The objectives of participatory meetings between stakeholders including agriculturists, government agents (such as sub-district agricultural and sub-district administrative officers) and academics from educational institutions, are to set weight importance for alternatives or six objective equations by using the FAHP method. Figure 1. shows the levels that meets the goal of the community, that is, having sustainable income from agricultural products. This comprises important criteria including economy and society (ES) with the highest weight value of 0.75 , which is higher than that for health and environment at 0.25 . When we consider sub-criteria, the calculation result reveals that in economic and social criteria, agriculturists give importance to price (p) criterion the most, followed by government support (gov). The health and environment criterion was considered important by agriculturists in regard to the chemical residue in their body (che) the most because they have above average chemical residue in their bodies.

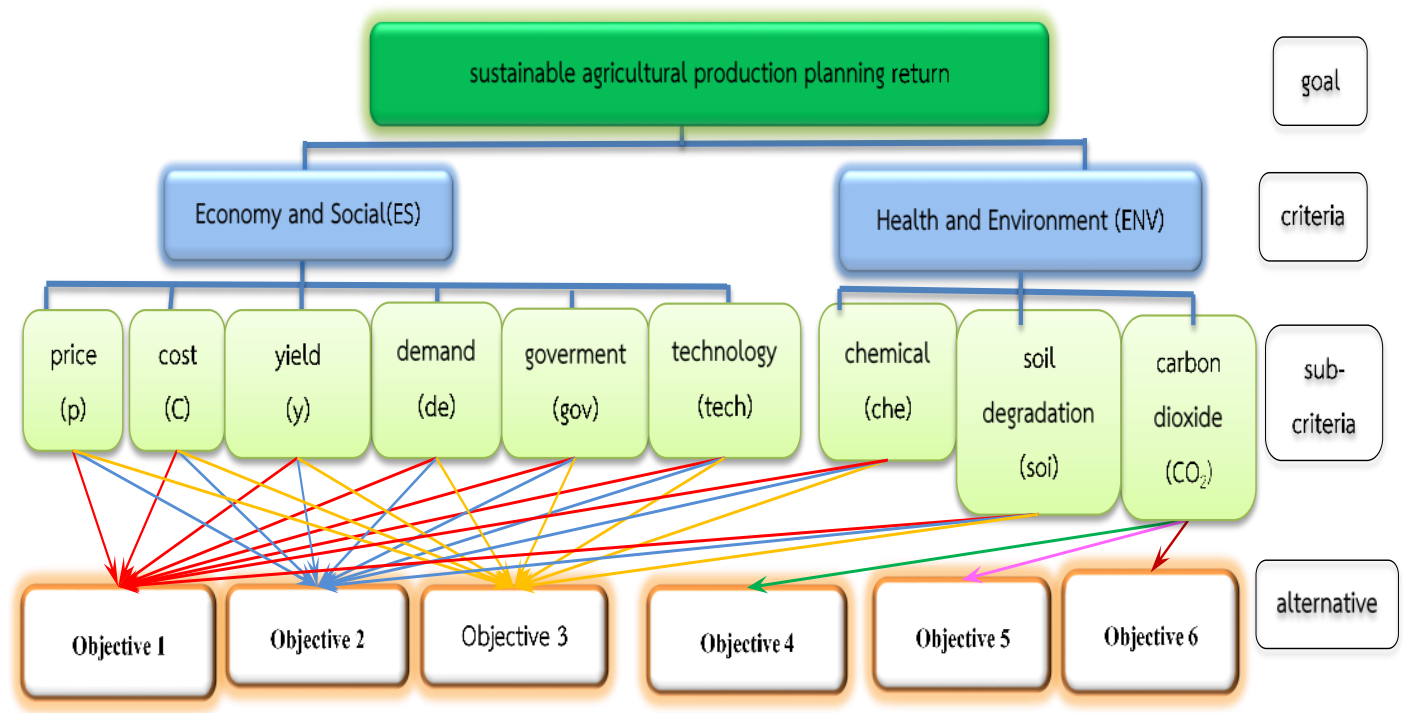

Figure 1. Hierarchical analysis of the sustainable agricultural production planning return

(Mae Faek Mai Sub-district, San Sai District, Chiang Mai Province) 
When considering the values for the global weighting of all six alternatives, the study revealed that the weight values of objectives 1-3 were more than 0.7 because community people placed importance on ES more than health and environment (objectives 4-6). The alternative that had the highest weight value was objective 1 (revenue from in-season glutinous rice and potato) because this alternative can achieve the goals for revenue and food sustainability at the community level, with a weight value of 0.412 , followed by objective 2 (revenue from inseason glutinous rice and maize for animal feed) and 3 (revenue from in-season and off-season glutinous rice) with weight values of 0.211 and 0.142 , respectively. This is because agriculturists experience uncertainty in regard to drought. Consequently, maize for animal feed from objective 2 is risky in terms of revenue. Regarding the health and environment criterion, the overall weight values of the alternatives for objectives 4-6 were less than 0.3 . This is because community people believed that the amount of $\mathrm{CO} 2$ released from agricultural activities did not significantly affect their living or economic benefits. The calculations revealed that objective 6 (CO2 from objective 3 ) had the highest volume of greenhouse gas. (1,977 kg CO2/Rai) followed by objective 4 (CO2 from objective 1) and 5 (CO2 from objective 2), respectively. Nevertheless, agriculturists still gave weight to objective 4 with a global weight value of 0.105 followed by objective 5 and 6 at 0.08 and 0.05 , respectively.

\subsection{Achieving the revenue goal of agriculturists and the approach for appropriate resource allocation}

From participatory meetings with agricultural and community representatives, the economic data collected by sub-district administrative office provides a range of data including the net revenue and amount of $\mathrm{CO} 2$ to set as goal values over 3 years for the MpMGP model. That is, objective 1 (in-season glutinous rice, potato) $3-50$ million baht, objective 2 (in-season glutinous, maize) and objective 3 (in-season and off-season glutinous rice) 1.5 - 30 million baht, while objectives 4-6 include the need to reduce the amount of CO2 by as much as possible. The range of goal values are similar for three alternatives i.e., $0.5-20$ million $\mathrm{kg} \mathrm{CO} 2$ and with setting controlling parameter $\lambda$ in EGP model to identify the philosophy of solution needed i.e., increase in revenue efficiency ( $\lambda$ increase to 1 ) or increase in equity for all objectives ( $\lambda$ reducing to 0 ). These results are shown in Figure 2.

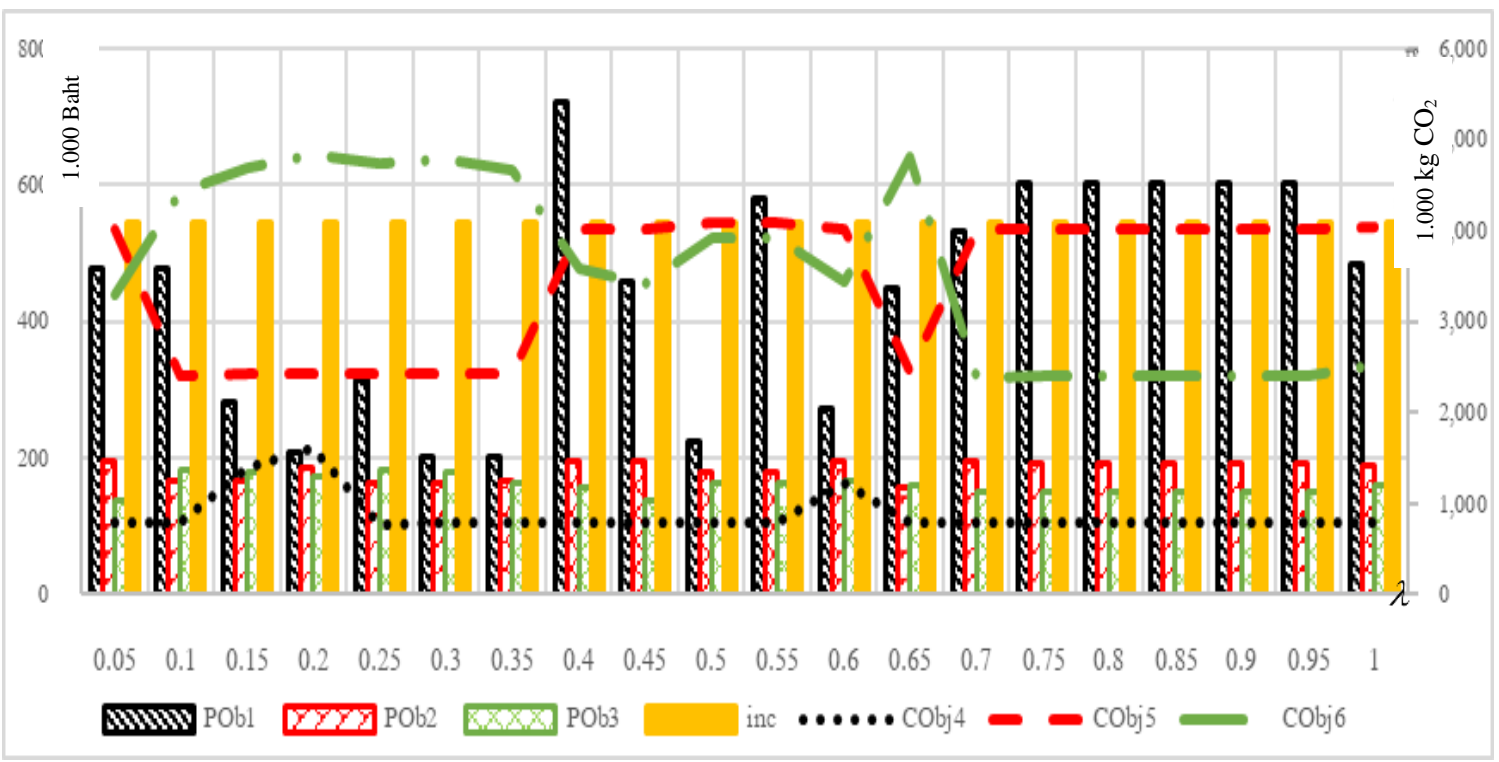

Figure 2. Return on household and amount of carbon dioxide emissions at various level of $\lambda$

In regard to the efficiency in achieving the goal of each objective, the results show that the alternative objective that had the highest weight value was chosen first, followed by the objective that had the second highest value. From Figure 2, revenue from objective 1 (Pob1) had a high value of 15 million baht/year or average income per household of 200,000 baht/year (at $\lambda \geq 0.7$ ) which is higher than the current average income of $180.000 \mathrm{baht} / \mathrm{year}$ (inc) (Chiang Mai Provincial Community Development, 2016). It also had the lowest emission of CO2 (CObj4). The second alternative is objective 2 (Pob2) which can make revenue per household at 66,000 baht/year (at $\lambda \geq 0.7$ ), but that must be traded off against the highest amount of CO2 emission (CObj5) compared with other objectives. Objective 3 (Prob3) yielded the lowest household revenue, with weight value at 0.14 (3rd rank) and a reduction of $50 \%$ for the amount of $\mathrm{CO} 2(\mathrm{CObj} 4)$. This results in a reduced use of land for growing according to objective 3 up to the point that it affects overall net revenue.

In regard to equity or balance in achieving the goal of each objective, the results from the model are to make balance of the sum of MpMGP (6 alternatives). The highest balance of the result would occur when a value of $\lambda=0.05$, which is the point that net revenue per household of alternative of objective1 (POb1) has a value at 158.6 
thousand baht/year (Figure 2 Pob1), which is lower than average agricultural household revenue (inc). Moreover, the $\mathrm{CO} 2$ amount tends to be increasing (objective 5 and 6) as a result of objectives 2 (POb2) and 3 (POb3).

Considering trade-off analysis, trade-offs occur between $\lambda=0.05$ and 0.65 , which are trade-offs between alternatives from the net revenue objective 1 (Pob1) and the amount of $\mathrm{CO} 2$ emission from objectives 5 (CObj5) and 6 (CObj6). The trade-offs had an average value of -49.26 , which means that the attempt to increase revenue from off-season glutinous and maize by 1 baht not only increases greenhouse gas, but also decreases the revenue from potato, on average, by 49 Baht.

From the estimated result of the study reveals that the overall use of the area reaches the highest value during year 2 in February - April, especially when setting the creation of the highest equity $(\lambda=0.05)$. Most of land use is for potato, maize for animal feed and in-season glutinous rice, totaling 1,600 Rai. When focusing on the highest efficiency $(\lambda=1)$, the land use is reduced to 897 Rai since most of the land is allocated to potato and in-season glutinous rice (objective 1) to achieve the goals of the highest net revenue and the lowest amount of $\mathrm{CO} 2$. In terms of water needs, February and August of every year are the period that need the greatest amount of water at up to 419 thousand cubic meters. This is because, at that time, there are growing activities of both in and offseason glutinous rice (objective 3). Glutinous rice needs much more water than other crops. Hired labor is in high demand between February and August every year because it is the period of growing activities for in and offseason glutinous rice. Moreover, in February, labor is much needed for potato production when compared to other periods.

\section{Conclusion}

This research employed the MCDM method, which comprises FAHP and MpMGP together with EGP. The results from FAHP shows that agriculturists placed most importance on revenue from growing in-season glutinous rice alternating with potato. This is followed by in-season glutinous rice alternating with maize, and lastly, inseason glutinous rice alternating with off-season glutinous rice. The $\mathrm{CO} 2$ that came from the growing process received low attention from agriculturists. The goal of increasing revenue together with reducing greenhouse gas emission can be achieved by using the philosophy of efficiency together with equity, that is, 1) focusing on the efficiency of revenue from in-season glutinous rice and potato can increase the average revenue per household the most at 200,000 baht per year while CO2 emissions would be the lowest when compared to the other alternatives; 2) attempting to increase equity from MCDM would result in greater emissions of $\mathrm{CO} 2$ because resources would be allocated to alternatives that have higher $\mathrm{CO} 2$ emissions, for example, in and off-season glutinous rice; 3) increasing the revenue from alternatives that yield lower revenue would result in trade-offs or opportunity cost (Beck et al., 2008) with alternatives that yield higher revenue. Consequently, the attempt to grow in-season glutinous rice and maize for animal feed not only results in increasing greenhouse gas emission, but also decreases revenue. Nevertheless, maize for animal fed does offer income stability when drought occurs.

Applying the MCDM approach and the results from the study in reality is necessary since it permits resource allocation in accord with Pareto optimality with consideration to major criteria in the economy, society, and the environment, and also requires community participation (Biswas and Pal, 2005). This supports government policy that encourages collaborative farming which yields the benefits of the economies of scale. Agriculturists can cooperate and thus become more influential in the management of production, marketing and technology. Moreover, the results of this study can help in estimating the effects and risks from crop growing and can assist in planning crops, which is in line with government policy of encouraging green economy and helping the local economy and community to be sustainable.

\section{Acknowledgement}

This research was supported by Research and Graduate Studies, Khon Kaen University, Thailand.

\section{References}

[1]. Aras, H., Erdoğmuş, Ş., \& Koç, E. (2004). Multi-criteria selection for a wind observation station location using analytic hierarchy process. Renewable Energy, 29 (8), 1383 - 1392.

[2]. Biswas, A., \& Pal, B. B. (2005). Application of fuzzy goal programming technique to land use planning in agricultural system. Omega, 33(5), 391-398.

[3]. Doukas, H. C., Andreas, B. M., \& Psarras, J. E. (2007). Multi-criteria decision aid for the formulation of sustainable technological energy priorities using linguistic variables. European Journal of Operational Research, 182(2), 844-855.

[4]. Irrigation Department. (2014). Crop co-efficient values (Kc) of 40 types of crops. Retrieved from http://water.rid.go.th/hwm/cropwater/iwmd/index_th.htm. 
[5]. Jones, D., Florentino, H., Cantane, D., \& Oliveira, R. (2016). An extended goal programming methodology for analysis of a network encompassing multiple objectives and stakeholders. European Journal of Operational Research, 255(3), 845-855.

[6]. Jovanović, M., Afgan, N., Radovanović, P., \& Stevanović, V. (2009). Sustainable development of the Belgrade energy system. Energy, 34(5), 532-539.

[7]. Land Development Department. (2007). Land use allocation. Retrived from http://www.geocities.com/nuntanap/info/gisldd.htm.

[8]. Ministry of Agriculture and Cooperatives. (2013). The study of green economy in context of agricultural sector. Retrieved from http://oldweb.oae.go.th/biae/download/Journals/Paper_Green\%20Economy.pdf/.

[9]. Newton, A. C., \& Cantarello, E. (2014). An Introduction to the Green Economy. London: Routledge.

[10]. Nonthapot, S. \& Thomya, W. (2020). The Effect of the Marketing Mix on the Demand of Thai and Foreign Tourists, Management Science Letters. 10(11), 2437-2446.

[11]. Nonthapot, S. \& Nasoontorn, A. (2020). The Effect of the Service Quality on Passengers' Satisfaction, Management Science Letters. 10(15), 3717-3722.

[12]. Pilavachi, P. A., Stephanidis, S. D., Pappas, V. A., \& Afgan, N. H. (2009). Multi-criteria evaluation of hydrogen and natural gas fuelled power plant technologies. Applied Thermal Engineering, 29(11-12), 2228-2234.

[13]. Provincial Community Development Office of Chiang Mai. (2019). Data on basic needs. Retrieved from http://chiangmai.cdd.go.th/ (15 August 2016).

[14]. Sakawa, M., Yano, H., \& Nishizaki, I., (2013). Linear and Multi-objective Programming with Fuzzy Stochastic Extensions, New York: Springer.

[15]. Sumrit, Detcharat. (2020) Supplier selection for vendor-managed inventory in healthcare using fuzzy multi-criteria decision-making approach. Decision Science Letters, 9(2): $\quad$ 233-256.

[16]. Stewart, T. J., Janssen, R., \& van Herwijnen, M. (2004). A genetic algorithm approach to multiobjective land use planning. Computers \& Operations Research, 31(14), 2293-2313.

[17]. Thailand Greenhouse Gas Management Organization. (2017). Data of coefficient value of green house gas emission (Emission Factor : EF. Retrieved from www.tgo.or.th/2015/thai/index.php.

[18]. Wang, J. - J., Jing, Y. - Y., Zhang, C. -F., Zhang, X. - T., \& Shi, G. -H. (2008). Integrated evaluation of distributed triple-generation systems using improved grey incidence approach. Energy, 33(9), 14271437. 